\title{
Characteristics of Herbal Medicine Users and Adverse Events Experienced in South Korea: A Survey Study
}

\author{
Soobin Jang, ${ }^{1,2}$ Kyeong Han Kim, ${ }^{3}$ Seung-Ho Sun, ${ }^{4}$ Ho-Yeon Go, ${ }^{5}$ Eun-Kyung Lee, \\ Bo-Hyoung Jang, ${ }^{1}$ Yong-Cheol Shin, ${ }^{1}$ and Seong-Gyu Ko ${ }^{1}$ \\ ${ }^{1}$ Department of Preventive Medicine, College of Korean Medicine, Kyung Hee University, 26 Kyungheedae-ro, \\ Dongdaemun-gu, Seoul 02447, Republic of Korea \\ ${ }^{2}$ KM Fundamental Research Division, Korea Institute of Oriental Medicine, 1672 Yuseongdae-ro, Yuseong-gu, \\ Daejeon 34054, Republic of Korea \\ ${ }^{3}$ Department of Preventive Medicine, College of Korean Medicine, Woosuk University, 61 Seonneomeo 3-gil, \\ Wansan-gu, Jeonju, Jeollabuk-do 54986, Republic of Korea \\ ${ }^{4}$ Department of Korean Internal Medicine, Sangji University Korean Medicine Hospital, 283 Woosan-dong, \\ Wonju 26338, Republic of Korea \\ ${ }^{5}$ Department of Korean Internal Medicine, College of Korean Medicine, Semyung University, \\ 579 Sinwoul-dong, Jecheon, Chungcheongbuk-do 27136, Republic of Korea \\ Correspondence should be addressed to Seong-Gyu Ko; epiko@khu.ac.kr
}

Received 26 December 2016; Accepted 29 March 2017; Published 10 April 2017

Academic Editor: Karin Kraft

Copyright (c) 2017 Soobin Jang et al. This is an open access article distributed under the Creative Commons Attribution License, which permits unrestricted use, distribution, and reproduction in any medium, provided the original work is properly cited.

\begin{abstract}
Background. This survey aimed to investigate the characteristics of users and nonusers of herbal medicine and the adverse events experienced due to herbal medicines in South Korea. Methods. The questionnaire consisted of safety, using experience, using type, usage and nonusage reason, purchase location, and adverse events of herbal medicine. The survey was administered by online. Results. Of the total 1,134 respondents, 726 (64.0\%) considered herbal medicine safe, and 693 (61.1\%) answered that they have taken herbal medicines within the past year. Most common place to purchase them was "TKM hospital or clinic" (63.6\%), and most participants $(72.2 \%)$ took a decoction from a TKM institution. The biggest reason for taking them was for "health improvement" (57.3\%), and the reasons for not using them was "medication not necessary" (63.7\%). Among those who took herbal medicines, 46 experienced adverse events, and the most frequently reported symptoms were digestive disorders (52.2\%). Of the 46 participants who experienced adverse events, 20 (43.5\%) were treated by TKM doctors. Conclusions. This study suggests that regulation of herbal medicines is needed in order to resolve problems related to the safety of herbal medicines.
\end{abstract}

\section{Background}

The global herbal medicine market has grown every year, and the total estimated retail sales of herbal supplements in the United States reached almost $\$ 7$ billion after increasing by $7.5 \%$ in 2015 [1]. The sales are anticipated to further grow to reach $\$ 5$ trillion by 2050 [2].

As the interest in herbal medicines increases, there is a growing need to ensure their safety. The goal of the World Health Organization (WHO) Traditional Medicine Strategy is to promote the safe and effective use of Traditional and Complementary Medicine (T\&CM). Regulations on the safety of herbal medicine have increased in order to achieve this goal. The numbers of policies and regulations to ensure the safety and efficacy of T\&CM were 69 and 119, respectively [3]. According to the Report on Usage and Consumption of Korean Medicines 2011 [4], approximately $22.4 \%$ of people who have experienced Korean Medicine hospitals or clinics answered that ensuring the safety of herbal medicines would lead to future improvements in Korean Medicine.

South Korea is a country with a long history of herbal medicine usage. However, until recently, there has not been a systematic report of adverse events, which would be the foundation of enhancing safety. According to the data of 
Korean Regional Pharmacovigilance Centers in 2007, there was only one case of adverse drug reaction reported from herbs among the observed 1,418 cases [5]. As a result of self-investigation of a university hospital, 28 adverse drug reactions occurred from herbal medicines in one Korean Medicine Hospital in South Korea from January 1, 2008, to February 29, 2012 [6].

This study surveyed in detail the characteristics of consumers in Korea and the adverse events from herbal medicines, as well as the perceived safety of products. The objective of this study was to investigate Korean consumers' usage patterns with respect to herbal medicines and to provide research-based evidence for enhancing their safety.

\section{Methods}

2.1. Study Design and Setting. This study was a survey of the characteristics of herbal medicine users in South Korea. The survey was conducted by Macromill Embrain (http://www .embrain.com), which is a professional survey research company that manages about $1,180,000$ online research panels in South Korea. The company recruited the participants with consideration of the age and sex distributions and informed them that responses had to be filled out for all our questions in the questionnaire. The participants were enrolled on a voluntary basis and there was no refusal rate. The survey was conducted anonymously between October 1 and 31, 2015.

2.2. Participants. There was no special method for determining the sample size; we only sought to have as many people as possible complete the survey during the survey period. The minimum number of participants was determined to be 1,000 , with additional recruitment on-going until the end of the study period. The participants were stratified based on gender and age to get the status of general population. Those under 20 years old and over 70 years old were excluded.

2.3. Questionnaire. The questionnaire was developed by five traditional Korean medicine (TKM) experts who discussed and selected investigation items. A draft questionnaire was developed through two rounds of review, placing emphasis on the easy comprehension of the questionnaire to gear to the general population. The experts examined face reliability as well as readability of the questionnaire. Then, a pilot test was conducted that targeted 10 people who were not medical practitioners. A group of experts collected feedback and completed the final version of the questionnaire.

The questionnaire consisted of two categories: (1) questions related to the herbal medicines usage over the past year and (2) questions related to adverse events experienced relating to the herbal medicines. The questionnaire is shown in Supplement 1 (in Supplementary Material available online at https://doi.org/10.1155/2017/4089019).

\subsection{Study Variables. The detailed variables are as follows:}

(1) Demographic information: sex, age, occupation, and education level
(2) Usage patterns: opinion on safety of herbal medicines, experiences related to taking herbal medicines, places from which the herbal medicines were purchased, the types of herbal medicines used, reasons for taking herbal medicines, and reasons for not taking herbal medicines

(3) Adverse events: experiences of adverse events relating to herbal medicines, types of adverse events, whether adverse events were reported, to which institutions the adverse events were reported, reasons for not reporting adverse events, how to deal with adverse events, and opinions on herbal medicines after experiencing adverse events

2.5. Statistical Analyses. A frequency analysis was performed for all variables. The chi-squared test was also employed in order to determine differences by sex, age, occupation, and education level. IBM SPSS ver. 18.0 (IBM Co., Armonk, NY, USA) was used for analysis.

2.6. Ethical Considerations. All participants were briefed with an explanation of the study's purpose prior to the initiation of the survey. Only those who voluntarily agreed to participate and to have their data collected to be published were enrolled in the study. This survey was conducted anonymously. The entire survey process was approved by the Institutional Review Board of Kyung Hee University (IRB number KHSIRB1-15-039).

\section{Results}

3.1. Basic Characteristics. There were total of 1,134 respondents, consisting of 591 (52.1\%) men and 543 (47.9\%) women. Table 1 presents the distribution of the participants' sex, age, occupation, and education level. The age distribution was as follows: 209 (18.4\%) were 20-29 years old, $237(20.9 \%)$ were $30-39$ years old, 277 (24.4\%) were $40-49$ years old, 253 (22.3\%) were 50-59 years old, and 158 (13.9\%) were 60-69 years old. Office worker was the most common occupation (34.6\%), and most participants $(79.7 \%)$ had a university degree.

Of the 1,134 respondents, there were 693 (61.1\%) who had taken herbal medicines within the past year and 441 (38.9\%) who had not. There was no difference in demographic factors between users and nonusers of herbal medicines (Table 2).

3.2. Opinion on Safety of Herbal Medicines. Of the total 1,134 participants, $726(64.0 \%)$ people responded that herbal medicine is safe and the remaining 408 (36.0\%) people considered herbal medicine unsafe. Women tended to distrust the safety of herbal medicines more compared to men, and those over the age of 50 were more skeptical of herbal medicine (Table 3 ).

3.3. Usage Patterns of Herbal Medicines. The most common place to purchase herbal medicines was TKM hospital or clinic $(63.6 \%)$. Pharmacy $(17.0 \%)$, traditional herb market $(17.0 \%)$, health food store $(14.6 \%)$, oriental pharmacy $(12.8 \%)$, home shopping $(11.0 \%)$, and hypermarket 
TABLE 1: Basic characteristics of respondents.

\begin{tabular}{|c|c|c|}
\hline Demographic characteristics & $n$ & $\%$ \\
\hline \multicolumn{3}{|l|}{ Sex } \\
\hline Men & 591 & 52.1 \\
\hline Women & 543 & 47.9 \\
\hline \multicolumn{3}{|l|}{ Age (years) } \\
\hline $20-29$ & 209 & 18.4 \\
\hline $30-39$ & 237 & 20.9 \\
\hline $40-49$ & 277 & 24.4 \\
\hline $50-59$ & 253 & 22.3 \\
\hline $60-69$ & 158 & 13.9 \\
\hline \multicolumn{3}{|l|}{ Occupation } \\
\hline Executives professionals & 214 & 18.9 \\
\hline Office workers & 392 & 34.6 \\
\hline Service sales workers & 83 & 7.3 \\
\hline Agriculture, forestry, and fishery workers & 4 & 0.4 \\
\hline Craft mechanical workers & 41 & 3.6 \\
\hline Simple labourers & 15 & 1.3 \\
\hline Self-employed, part-time employees, and freelancers & 25 & 2.2 \\
\hline Students, housewives, and unemployed & 360 & 31.7 \\
\hline \multicolumn{3}{|l|}{ Level of education } \\
\hline Middle school & 9 & 1.1 \\
\hline High school & 218 & 19.2 \\
\hline College & 784 & 69.1 \\
\hline Graduate school & 120 & 10.6 \\
\hline Total & 1134 & 100.0 \\
\hline
\end{tabular}

(11.0\%) were reported as other places to purchase them. The most predominantly used type of herbal medicines was a decoction from TKM institutions (72.2\%). Other types of herbal medicines were crude herbs, which are mainly used in food or tea $(35.8 \%)$, health food $(28.6 \%)$, national insurance-covered herbal medicines from TKM institutions (15.3\%), national insurance-covered herbal medicines from pharmacies (15.0\%), and others (0.8\%) (Table 4).

The reasons for taking the medication were as follows: $57.3 \%$ for "health improvement," $40.3 \%$ for "treatment in KM hospitals or clinics," $34.8 \%$ due to "recommendation from acquaintance," $9.5 \%$ due to "recommendation from a pharmacist," and others. The reasons for not taking herbal medicines were "medication was not necessary" (63.7\%), "uncertainty of origins" (35.4\%), "expensive prices" (25.9\%), "anxiety related to the possibility of harmful substances" (25.9\%), "anxiety related to the possibility of adverse events" (23.8\%), and others (Table 4 ). Figures 1-3 present the usage patterns and reasons for taking of herbal medicines according to age groups in detail. There were no remarkable differences by age.

3.4. Adverse Events and Their Reporting. Of the 693 participants who have taken herbal medicines within the past year, $46(6.6 \%)$ responded that they had experienced adverse events from herbal medicines. The most common symptom

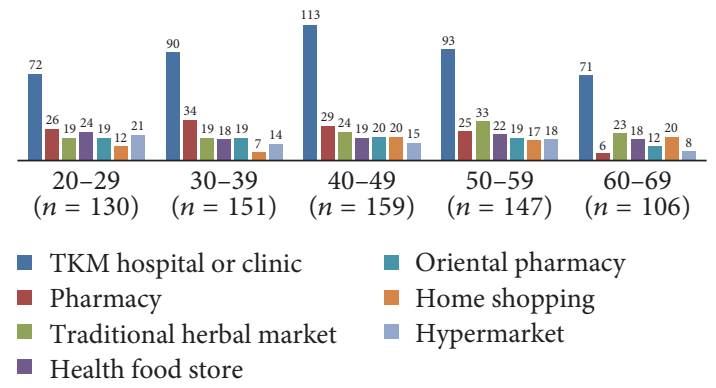

FIGURE 1: Location where herbal medicines were purchased according to age groups.

was digestive disorders (52.2\%), followed by skin disorders (34.8\%) and nervous disorders (23.9\%) (Table 5).

After experiencing an adverse event, 20 participants (43.5\%) were treated by KM doctors, 13 (28.5\%) did not take any action, and $12(26.1 \%)$ requested a refund. Seventeen participants $(37.0 \%)$ felt that expert counselling may be needed after experiencing adverse events, and 14 (30.4\%) responded that drugs can have adverse events and that they would continue taking herbal medicines. However, 13 people $(28.3 \%)$ responded that they cannot trust herbal medicines anymore and they would not continue taking herbal medicines. Of the 46 respondents who experienced 
TABLE 2: Basic characteristics of herbal medicines users and nonusers.

\begin{tabular}{|c|c|c|c|}
\hline Demographic characteristics & Users $(n=693,61.1 \%)$ & Nonusers $(n=441,38.9 \%)$ & ${ }^{*} P$ value \\
\hline \multicolumn{4}{|l|}{ Sex } \\
\hline Men & $361(52.1)$ & $230(52.2)$ & \multirow{2}{*}{1.000} \\
\hline Women & $332(47.9)$ & $211(47.8)$ & \\
\hline \multicolumn{4}{|l|}{ Age (years) } \\
\hline $20-29$ & $130(18.8)$ & $79(17.9)$ & \multirow{5}{*}{0.221} \\
\hline $30-39$ & $151(21.8)$ & $86(19.5)$ & \\
\hline $40-49$ & $159(22.9)$ & $118(26.8)$ & \\
\hline $50-59$ & $147(21.2)$ & $106(24.0)$ & \\
\hline $60-69$ & $106(15.3)$ & $52(11.8)$ & \\
\hline \multicolumn{4}{|l|}{ Occupation } \\
\hline Executives professionals & $146(21.1)$ & $68(15.4)$ & \multirow{8}{*}{0.229} \\
\hline Office workers & $244(35.2)$ & $148(33.6)$ & \\
\hline Service sales workers & $45(6.5)$ & $38(8.6)$ & \\
\hline Agriculture, forestry, and fishery workers & $2(0.3)$ & $2(0.5)$ & \\
\hline Craft mechanical workers & $23(3.3)$ & $18(4.1)$ & \\
\hline Simple labourers & $7(1.0)$ & $8(1.8)$ & \\
\hline Self-employed, part-time employees, and freelancers & $15(2.2)$ & $10(2.3)$ & \\
\hline Students, housewives, and unemployed & $211(30.4)$ & $149(33.8)$ & \\
\hline \multicolumn{4}{|l|}{ Level of education } \\
\hline Middle school & $6(0.9)$ & $6(1.3)$ & \multirow{4}{*}{0.172} \\
\hline High school & $119(17.2)$ & $99(22.4)$ & \\
\hline College & $490(70.7)$ & $294(66.7)$ & \\
\hline Graduate school & $78(11.3)$ & $42(9.5)$ & \\
\hline
\end{tabular}

All data are in $n(\%)$.

${ }^{*}$ Chi-square test was performed.

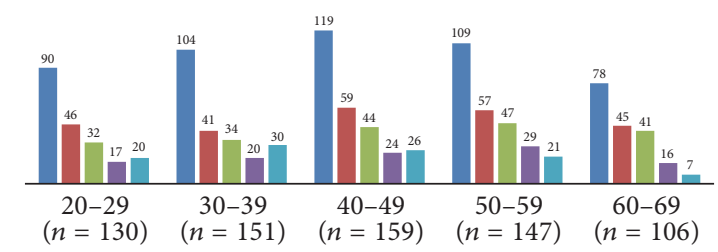

- Decoction from a TKM institution

- Crude herb (used for cuisine or tea)

- Health food

- National insurance-covered herbal medicines from TKM institutions

- National insurance-covered herbal medicines from pharmacies

* TKM: traditional Korean medicine

FIgURE 2: Types of herbal medicines according to age groups.

adverse events, 14 (30.4\%) reported their adverse events and $20(43.5 \%)$ did not because they had little information regarding to whom the report should be made (Table 6).

\section{Discussion}

This study described the basic characteristics of those who had taken herbal medicines and those who had not taken them, the places that herbal medicines were purchased, the reasons for taking or not taking herbal medicine, and adverse events experienced due to herbal medicines and

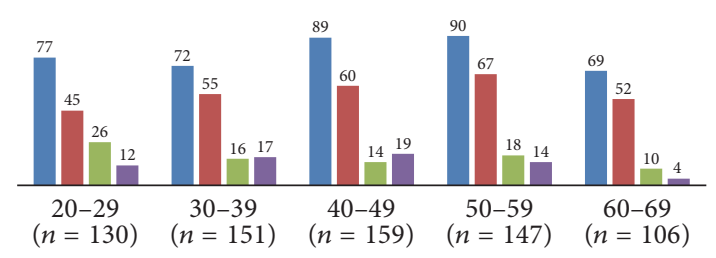

- Health improvement

- Recommendation from acquaintance

- Treatment from a Korean medicine institution

- Recommendation from pharmacist

FIGURE 3: Reasons for taking herbal medicines according to age groups.

how the adverse events were addressed. In previous studies $[7,8]$, elderly people tended to visit TKM institutions more frequently than younger people. However, age was not a factor that affected taking herbal medicines in this survey.

There have been several surveys in the past demonstrating consumers' opinions about the safety of herbal medicines [9-11]. According to surveys of Serbia [9] and Saudi Arabia [10], 73.3\% (211) of Serbian respondents and 81.2\% (239) of Saudi Arabian respondents considered that the use of herbal medicines and herbal dietary supplements is harmless, respectively. Meanwhile, only $12.1 \%$ (88) of Lebanese respondents perceived that herbal products sold in Lebanon are pure [11]. 
TABLE 3: Opinion on safety of herbal medicines.

\begin{tabular}{|c|c|c|c|}
\hline & $\begin{array}{l}\text { Herbal medicine is safe } \\
\quad(n=726,64.0 \%)\end{array}$ & $\begin{array}{c}\text { Herbal medicine is not } \\
\text { safe }(n=408,36.0 \%)\end{array}$ & ${ }^{*} P$ value \\
\hline \multicolumn{4}{|l|}{ Sex } \\
\hline Men & $430(59.2)$ & $161(39.5)$ & \multirow{2}{*}{$>0.001$} \\
\hline Women & $296(40.8)$ & $247(60.5)$ & \\
\hline \multicolumn{4}{|l|}{ Age (years) } \\
\hline $20-29$ & $154(21.2)$ & $55(13.5)$ & \multirow{5}{*}{$>0.001$} \\
\hline $30-39$ & $166(22.9)$ & $71(17.4)$ & \\
\hline $40-49$ & $176(24.2)$ & $101(24.8)$ & \\
\hline $50-59$ & $148(20.4)$ & $105(25.7)$ & \\
\hline $60-69$ & $82(11.3)$ & $76(18.6)$ & \\
\hline \multicolumn{4}{|l|}{ Occupation } \\
\hline Executives professionals & $145(20.0)$ & $69(16.9)$ & \multirow{8}{*}{0.142} \\
\hline Office workers & $252(34.7)$ & $140(34.3)$ & \\
\hline Service sales workers & $52(7.2)$ & $31(7.6)$ & \\
\hline Agriculture, forestry, and fishery workers & $4(0.6)$ & 0 & \\
\hline Craft mechanical workers & $32(4.4)$ & $9(2.2)$ & \\
\hline Simple labourers & $11(1.5)$ & $4(1.0)$ & \\
\hline Self-employed, part-time employees, and freelancers & $14(1.9)$ & $11(2.7)$ & \\
\hline Students, housewives, and unemployed & $216(29.8 \%)$ & $144(35.3)$ & \\
\hline \multicolumn{4}{|l|}{ Level of education } \\
\hline Middle school & $10(1.4)$ & $2(0.4)$ & \multirow{4}{*}{0.610} \\
\hline High school & $138(19.0)$ & $80(19.6)$ & \\
\hline College & $499(68.7)$ & $285(69.9)$ & \\
\hline Graduate school & $79(10.9)$ & $41(10.0)$ & \\
\hline
\end{tabular}

All data are in $n$ (\%).

${ }^{*}$ Chi-square test was performed.

Most respondents purchased herbal medicines from TKM institutions (Table 4). This observation can be explained by the Korean health system. South Korea has adopted a dual healthcare system in which both Western medicine and TKM are permitted as legal medical care [12]. Herbal-drugs are separated from herbal supplements and are prescribed by TKM practitioners or sold over-the-counter in pharmacies. Herbal supplements, such as red ginseng, are sold in pharmacies, hypermarkets, or through home shopping channels. Traditional herb markets and health food stores generally sell crude herbs or self-made decoctions. Oriental pharmacies can provide 100 popular herbal medications without TKM practitioners' prescriptions [13].

Regarding the type of herbal medicines, a decoction from a TKM institution was the most frequently used, reflecting the preference of Koreans (Table 4). Korean people may recognise that a decoction is a typical herbal medicine that is more effective than other formulations, such as powders, pills, and capsules. On the other hand, in Japan, the proportion of the market of herbal medicines covered by insurance is large, and production costs of insured herbal medicines account for $84.2 \%$ of the entire herbal medicine market [14].

The main reasons for taking herbal medicines included "health improvement" and "treatment in TKM hospitals or clinics" (Table 4). Herbal medicine is recognised as a tool for both preventive medicine and disease treatment in South Korea. Meanwhile, traditional medicine is still one of the primary sources of health care in Africa and some other developing countries, and it is used as complementary therapy in North America and many European countries [3]. In South Korea, both uses are well-balanced thanks to the health system and cultural influences.

This study also analysed the usage patterns of difference by age (Figures 1-3). There is no noticeable outcome, though those 60-69 tend to use crude herb and health food more. It may affect their negative perception on safety of herbal medicines (Table 3). Crude herb is not purified and its safety is not proven. It also includes roots, leaves, and flowers that have been taken from the wild; accordingly, the safety of crude herb can be suspicious.

Of the 1,134 respondents, 441 (38.9\%) had not taken herbal medicines in the past year (Table 2). Among the reasons for not taking herbal medicine, "uncertainty of origins," "anxiety related to the possibility of harmful substances," "anxiety related to the possibility of adverse events," and "distrust of expiry date" were due to disbelief in the safety of herbal medicines. It is necessary to improve the safety of herbal medicines in order for the herbal medicine market 
TABLE 4: Patterns of herbal medicine use and reasons for taking or not taking herbal medicines.

\begin{tabular}{|c|c|c|}
\hline $\begin{array}{l}\text { Question } \\
\text { (number of respondents) }\end{array}$ & Response & $n(\%)$ \\
\hline \multirow{2}{*}{$\begin{array}{l}\text { Have you taken herbal medicines in the } \\
\text { past year? }(n=1134)\end{array}$} & Yes & $693(61.1)$ \\
\hline & No & $441(38.9)$ \\
\hline \multirow{8}{*}{$\begin{array}{l}\text { Location where herbal medicines were } \\
\text { purchased* }^{*}(n=693)\end{array}$} & TKM hospital or clinic & $441(63.6)$ \\
\hline & Pharmacy & $120(17.0)$ \\
\hline & Traditional herbal market & $118(17.0)$ \\
\hline & Health food store & $101(14.6)$ \\
\hline & Oriental pharmacy & $89(12.8)$ \\
\hline & Home shopping & $76(11.0)$ \\
\hline & Hypermarket & $76(11.0)$ \\
\hline & Other & $8(1.1)$ \\
\hline \multirow{6}{*}{ Types of herbal medicines $^{*}(n=693)$} & Decoction from a TKM institution & $500(72.2)$ \\
\hline & Crude herb (used for cuisine or tea) & $248(35.8)$ \\
\hline & Health food & $198(28.6)$ \\
\hline & $\begin{array}{l}\text { National insurance-covered herbal } \\
\text { medicines from TKM institutions }\end{array}$ & $106(15.3)$ \\
\hline & $\begin{array}{l}\text { National insurance-covered herbal } \\
\text { medicines from pharmacies }\end{array}$ & $104(15.0)$ \\
\hline & Other & $6(0.8)$ \\
\hline \multirow{5}{*}{$\begin{array}{l}\text { Reasons for taking herbal medicines* } \\
(n=693)\end{array}$} & Health improvement & $397(57.3)$ \\
\hline & $\begin{array}{c}\text { Treatment from a Korean medicine } \\
\text { institution }\end{array}$ & $279(40.3)$ \\
\hline & Recommendation from acquaintance & $84(12.1)$ \\
\hline & Recommendation from pharmacist & $66(9.5)$ \\
\hline & Other & $6(0.7)$ \\
\hline \multirow{8}{*}{$\begin{array}{l}\text { Reasons for not taking herbal medicines* } \\
(n=441)\end{array}$} & Medication not necessary & $281(63.7)$ \\
\hline & Uncertainty of origins & $156(35.4)$ \\
\hline & Expensive prices & $114(25.9)$ \\
\hline & $\begin{array}{l}\text { Anxiety about possible harmful } \\
\text { substances }\end{array}$ & $105(23.8)$ \\
\hline & Anxiety about possible adverse events & $59(13.4)$ \\
\hline & Disbelief regarding expiry date & $41(9.3)$ \\
\hline & No effectiveness & $39(8.8)$ \\
\hline & Other & $7(1.6)$ \\
\hline
\end{tabular}

${ }^{*}$ Multiple responses possible; TKM: traditional Korean medicine.

to grow. In South Korea, regulations on manufacturing and quality control of herbal medications were established in 2012, and they became fully mandatory in 2015 [15]. Health food is subject to the Good Manufacturing Practices (GMP) of the Ministry of Food and Drug Safety (MFDS) [16]. However, there is no safety control system for herbal medicines distributed via other routes. In Japan, unlike in South Korea, herbal medicines are divided into 210 over-thecounter Kampo products, crude drugs, and Kampo extracts and Western traditional herbal products, which are separately managed according to the national system [17].

Adverse events from herbal medicines reported by 46 participants $(6.6 \%$ of herbal medicines users) primarily included digestive, skin, and nervous disorders (Table 5). Liver toxicity of herbal medicines is controversial when it comes to the safety of herbal medicine [18]. However, only 4 cases of liver disorders were reported among the total 77 cases. According to previous studies [6, 19], the most frequently reported adverse drug reactions in a single hospital were gastrointestinal disorders and skin reactions, similar to the results in our study.

Although the Korean adverse drug reaction surveillance system was established in 1988 [20], it is not appropriate for reporting adverse events due to herbal medicines. Since 2012, adverse reactions from approved herbal-drugs have been reported to the Korea Adverse Event Reporting System (KAERS). However, not every herbal medicine is registered in that system, and the formulation of decoctions has not been applicable. The problem about national pharmacovigilance system of South Korea was also raised in prior study [21]. On 
TABLE 5: The number of adverse events due to herbal medicines.

\begin{tabular}{|c|c|c|}
\hline $\begin{array}{l}\text { Question } \\
\text { (number of respondents) }\end{array}$ & Response & $n(\%)$ \\
\hline \multirow{2}{*}{$\begin{array}{l}\text { Have you experienced adverse events from herbal } \\
\text { medicines in the past year? }(n=693)\end{array}$} & Yes & $46(6.6)$ \\
\hline & No & $647(93.4)$ \\
\hline \multirow{12}{*}{$\begin{array}{l}\text { What types of adverse events have you } \\
\text { experienced?* }(n=46)\end{array}$} & Digestive system & $24(52.2)$ \\
\hline & Skin & $16(34.8)$ \\
\hline & Nervous disorder & $11(23.9)$ \\
\hline & Systemic disorder & $6(13.0)$ \\
\hline & Liver & $4(8.7)$ \\
\hline & ENT and eye & $3(6.5)$ \\
\hline & Cardiovascular system & $3(6.5)$ \\
\hline & Circulatory system & $2(4.3)$ \\
\hline & Kidney & $2(4.3)$ \\
\hline & Urinary system & $2(4.3)$ \\
\hline & Musculoskeletal system & $2(4.3)$ \\
\hline & Respiratory system & $2(4.3)$ \\
\hline
\end{tabular}

${ }^{*}$ Multiple responses possible; ENT, ear, nose, and throat.

TABLE 6: Behaviours and opinions related to herbal medicine after experiencing adverse events.

\begin{tabular}{|c|c|c|}
\hline Question (number of respondents) & Response & $n(\%)$ \\
\hline \multirow{2}{*}{ Did you report adverse events? $(n=46)$} & Yes & $14(30.4)$ \\
\hline & No & $32(69.6)$ \\
\hline \multirow{8}{*}{$\begin{array}{l}\text { To whom did you report adverse } \\
\text { events?* }(n=14)\end{array}$} & TKM institution & $10(71.4)$ \\
\hline & WM institution & $3(21.4)$ \\
\hline & Pharmacy & $3(21.4)$ \\
\hline & Public health centre & $2(14.3)$ \\
\hline & Ministry of Health and Welfare & $2(14.3)$ \\
\hline & Korea Consumer Agency & $1(7.1)$ \\
\hline & KIDS & $1(7.1)$ \\
\hline & MFDS & $1(7.1)$ \\
\hline \multirow{3}{*}{$\begin{array}{l}\text { Why did you not report adverse events? } \\
(n=32)\end{array}$} & I did not know where to report & $20(62.5)$ \\
\hline & I felt it was unnecessary & $7(21.9)$ \\
\hline & I felt lazy & $5(15.6)$ \\
\hline \multirow{5}{*}{$\begin{array}{l}\text { How did you deal with adverse } \\
\text { events? }{ }^{*}(n=46)\end{array}$} & Consulted with TKM doctors & $20(43.5)$ \\
\hline & Nothing specific & $13(28.3)$ \\
\hline & Requested refund & $12(26.1)$ \\
\hline & Consulted with WM doctors & $7(15.2)$ \\
\hline & Consulted with pharmacist & $3(6.5)$ \\
\hline \multirow{4}{*}{$\begin{array}{l}\text { What did you think after the adverse } \\
\text { events? }(n=46)\end{array}$} & I need to see an expert & $17(37.0)$ \\
\hline & $\begin{array}{c}\text { Drugs can have adverse events and I } \\
\text { am going to continue taking herbal } \\
\text { medicines }\end{array}$ & $14(30.4)$ \\
\hline & $\begin{array}{l}\text { I cannot trust herbal medicines } \\
\text { anymore and I am not going to take } \\
\text { herbal medicines }\end{array}$ & $13(28.3)$ \\
\hline & I do not know & $2(4.3)$ \\
\hline
\end{tabular}

${ }^{*}$ Multiple responses possible. TKM: traditional Korean medicine; WM: western medicine; KIDS: Korea Institute of Drug Safety and Risk Management; MFDS: Ministry of Food and Drug Safety. 
the other hand, in Taiwan, the compositions and formulations of herbal medicines are included when reporting adverse drug reactions [22].

After experiencing adverse events, the majority of respondents $(20 ; 43.5 \%$ of adverse event experiencers) visited TKM practitioners, and 17 (37.0\%) felt that expert counsel would be necessary (Table 6). These results suggest that the role of TKM practitioners is important when adverse events occur. Moreover, only 14 people (30.4\% of adverse events experiencers) reported their adverse events, and only one person reported it to the Korea Institute of Drug Safety and Risk Management (KIDS) correctly. Therefore, both TKM practitioners and consumers need to receive appropriate education for responding to adverse events due to herbal medicines. Additionally, the reliability on herbal medicines was reduced for 13 respondents after they experienced adverse events (28.3\% of adverse events experiencers), and they responded that they would not take any other herbal medicines. Such behaviours may lead to a decreased consumption of herbal medicines; consequently, the safety of herbal medicines is vitally important.

There are limitations of this survey study. Firstly, a recall bias may exist because this study was based on a retrospective survey. Secondly, there is a possibility of response bias because the participants are rather highly educated. This is because having recruited the participants through an online research company and the sample may not be representative of the general population. Lastly, the perception of the range of herbal medicines varies among Koreans. Some people only recognise herbal medicines from TKM institutions as herbal medicines, while others take into account every type of herb.

Nonetheless, this study is meaningful in that there are no previous surveys to date that systematically investigated experiences and opinions about herbal medicines. This survey, unlike other consumer surveys, included not only herbal medicines users but also nonusers as participants, which increased the representativeness of the general population.

\section{Conclusions}

This survey analysed the usage of herbal and medicinal products in South Korea. This study showed the demographic differences between herbal medicine users and nonusers, opinions on safety of herbal medicines, experiences of using herbal medicines, and adverse events experienced from using herbal medicines. The major reasons for not taking herbal medicines were based on a disbelief in their safety. Therefore, it is important to ensure not only the efficacy but also the safety of herbal medicines in order to expand herbal product markets. Specific regulations on herbal medicines are needed to resolve problems with their origins, possibility of containing harmful substances, and the expiry date.

\section{Abbreviations}

WHO: World Health Organization

T\&CM: Traditional and Complementary Medicine

TKM: Traditional Korean medicine
GMP: Good Manufacturing Practice

MFDS: Ministry of Food and Drug Safety

KAERS: Korea Adverse Event Reporting System

KIDS: Korea Institute of Drug Safety and Risk Management.

\section{Ethical Approval}

This survey was approved by Institutional Review Board of Kyung Hee University (IRB no. KHSIRB1-15-039).

\section{Consent}

This study did not contain any individual person's data; however, it was notified that collected data would be published. All participants voluntarily agreed to participate in this survey.

\section{Conflicts of Interest}

The authors declare that there are no conflicts of interest regarding the publication of this paper.

\section{Authors' Contributions}

Soobin Jang and Kyeong Han Kim drafted the manuscript. Eun-Kyung Lee and Seung-Ho Sun managed entire process of survey and extracted the data. Bo-Hyoung Jang and Ho-Yeon Go organized and conducted the study. Yong-Cheol Shin and Seong-Gyu Ko supervised the study. All authors read and approved the final manuscript.

\section{Acknowledgments}

This study was supported by a grant from the Ministry of Food and Drug Safety, Republic of Korea (15172 Natural Products 197).

\section{References}

[1] T. K. K. Smith, V. Eckl, and J. Johnson, "Sales of herbal dietary supplements in US increased $7.5 \%$ in 2015 consumers spent $\$ 6.92$ billion on herbal supplements in 2015, marking the 12th consecutive year of growth," HerbalGram, vol. 111, pp. 67-73, 2016.

[2] T. Citarasu, "Herbal biomedicines: a new opportunity for aquaculture industry," Aquaculture International, vol. 18, no. 3, pp. 403-414, 2010.

[3] World Health Organization, WHO Traditional Medicine Strategy 2014-2023, World Health Organization, Geneva, Switzerland, 2013.

[4] Ministry of Health and Welfare, Report on the Usage and Consumption of Korean Medicine (2011), 2011.

[5] S. Y. Ha and K. W. Kang, "Two cases of lead poisoning after taking herb pills hwangdan (red lead)," Korean Journal of Pediatrics, vol. 22, no. 1, pp. 64-70, 1979.

[6] Y. J. Kwon, W. K. Cho, and C. H. Han, "Status of herbaldrug-associated adverse drug reactions voluntarily reported by EMR," The Journal of Korean Oriental Internal Medicine, vol. 33, no. 4, pp. 485-497, 2012. 
[7] J. Yoon, H. Park, C. Chu, S.-Y. Choi, K. Lee, and S. Lee, "A study on the characteristics of infrequent and frequent outpatients visiting Korean traditional medical facilities," Osong Public Health and Research Perspectives, vol. 6, no. 3, pp. 170-183, 2015.

[8] J.-M. Woo, E.-J. Park, M. Lee, M. Ahn, S. Kwon, and K. H. Koo, "Changes in attitudes toward and patterns in traditional Korean medicine among the general population in South Korea: a comparison between 2008 and 2011," BMC Complementary and Alternative Medicine, vol. 14, article 436, 2014.

[9] I. Samojlik, V. Mijatović, N. Gavarić, S. Krstin, and B. Božin, "Consumers' attitude towards the use and safety of herbal medicines and herbal dietary supplements in Serbia," International Journal of Clinical Pharmacy, vol. 35, no. 5, pp. 835-840, 2013.

[10] A. K Suleiman, "Attitudes and beliefs of consumers of herbal medicines in Riyadh, Saudi Arabia," Journal of Community Medicine \& Health Education, vol. 4, article 269, 2014.

[11] G. El Khoury, W. Ramadan, and N. Zeeni, "Herbal products and dietary supplements: a cross-sectional survey of use, attitudes, and knowledge among the Lebanese population," Journal of Community Health, vol. 41, no. 3, pp. 566-573, 2016.

[12] H. Lee, "The globalization of East Asian traditional medicine and the change of medical hegemony," Society and Theory, vol. 22, no. 5, pp. 377-398, 2013.

[13] Pharmaceutical Affairs Law (Republic of Korea) article 23, http:// www.law.go.kr/lsInfoP.do?lsiSeq=178173\&efYd=20161230\#0000.

[14] Japanese Kampo Medicines Manufactures Association, Annual Report on Pharmaceutical Industry Production Statistics, 2014.

[15] Ministry of Food and Drug Safety, Guideline on Good Manufacturing Practice of Herbal Medicines, 2013.

[16] Ministry of Food and Drug Safety, http://www.mfds.go.kr.

[17] H. Maegawa, T. Nakamura, and K. Saito, "Regulation of traditional herbal medicinal products in Japan," Journal of Ethnopharmacology, vol. 158, part B, pp. 511-515, 2014.

[18] Y. J. Yun, B. C. Shin, M. S. Lee, S. I. Cho, J. H. Park, and H. J. Lee, "Systematic review of the cause of drug-induced liver injuries in Korean literature," Journal of Korean Medicine, vol. 30, no. 2, pp. 30-45, 2009.

[19] M. Kim and C. Han, "Analysis of herbal-drug-associated adverse drug reactions using data from spontaneous reporting system in electronic medical records," Journal of Korean Medicine, vol. 36, no. 1, pp. 45-60, 2015.

[20] N.-K. Choi and B.-J. Park, "Adverse drug reaction surveillance system in Korea," Journal of Preventive Medicine and Public Health, vol. 40, no. 4, pp. 278-284, 2007.

[21] H.-K. Shin, S.-J. Jeong, D. S. Huang, B.-K. Kang, and M. S. Lee, "Usage patterns and adverse experiences in traditional Korean medicine: results of a survey in South Korea," BMC Complementary and Alternative Medicine, vol. 13, article 340, 2013.

[22] Taiwanese Ministry of Health and Welfare, http://www.mohw .gov.tw/cht/DOCMAP/DM1.aspx?f_list_no=205. 


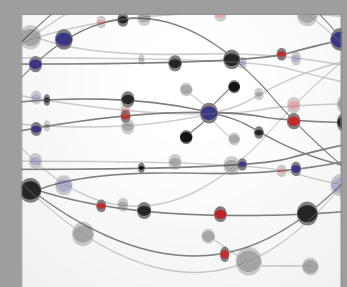

The Scientific World Journal
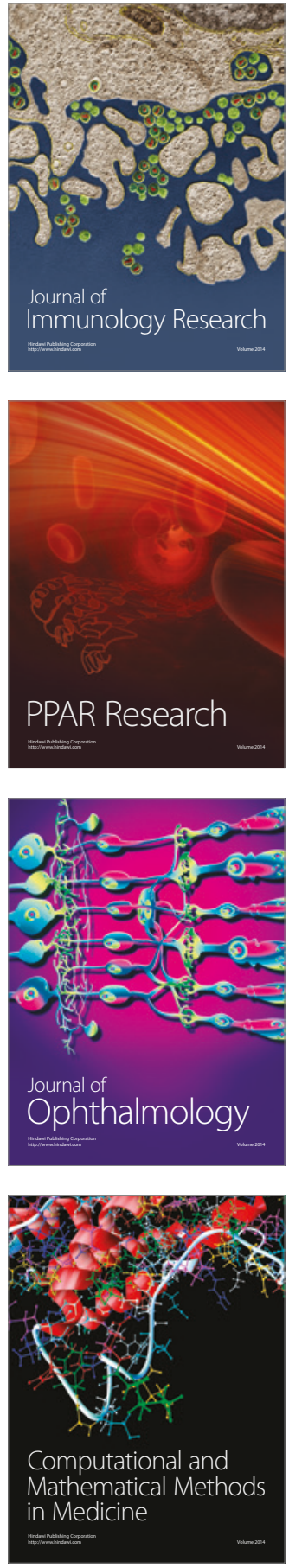

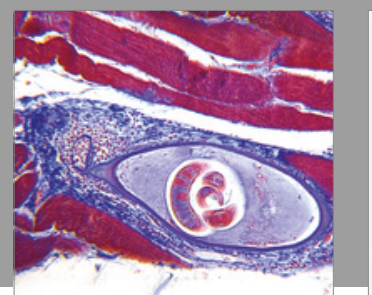

Gastroenterology Research and Practice
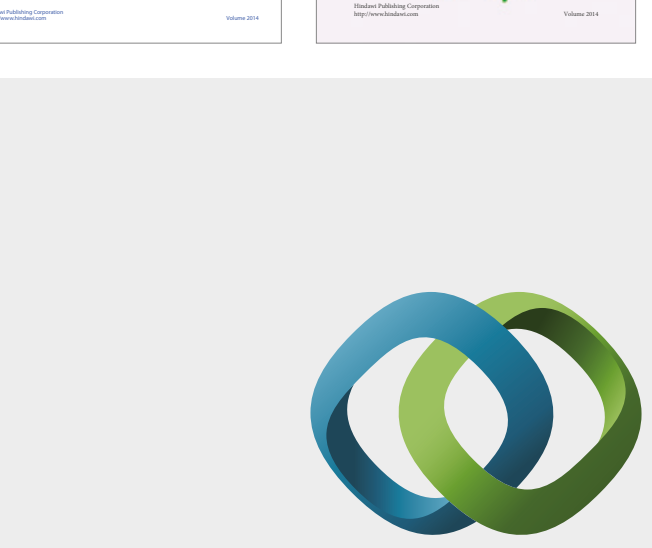

\section{Hindawi}

Submit your manuscripts at

https://www.hindawi.com
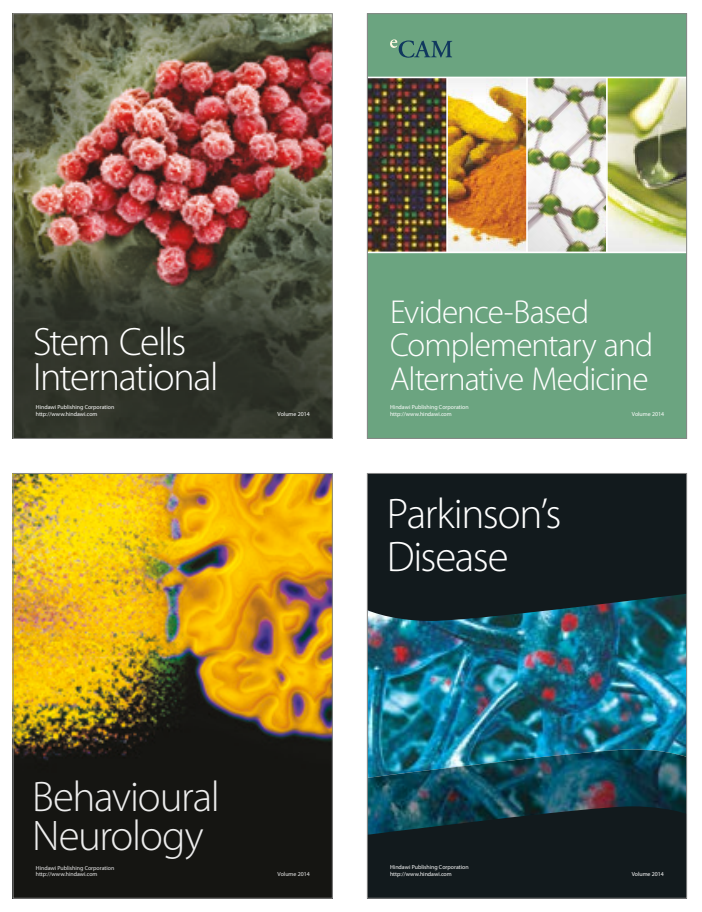
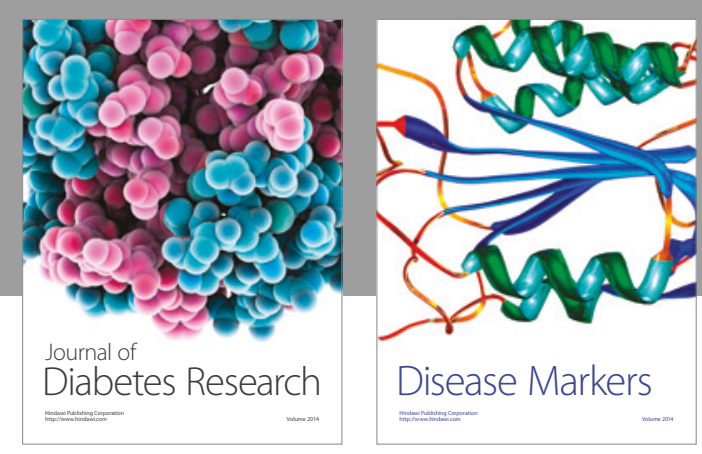

Disease Markers
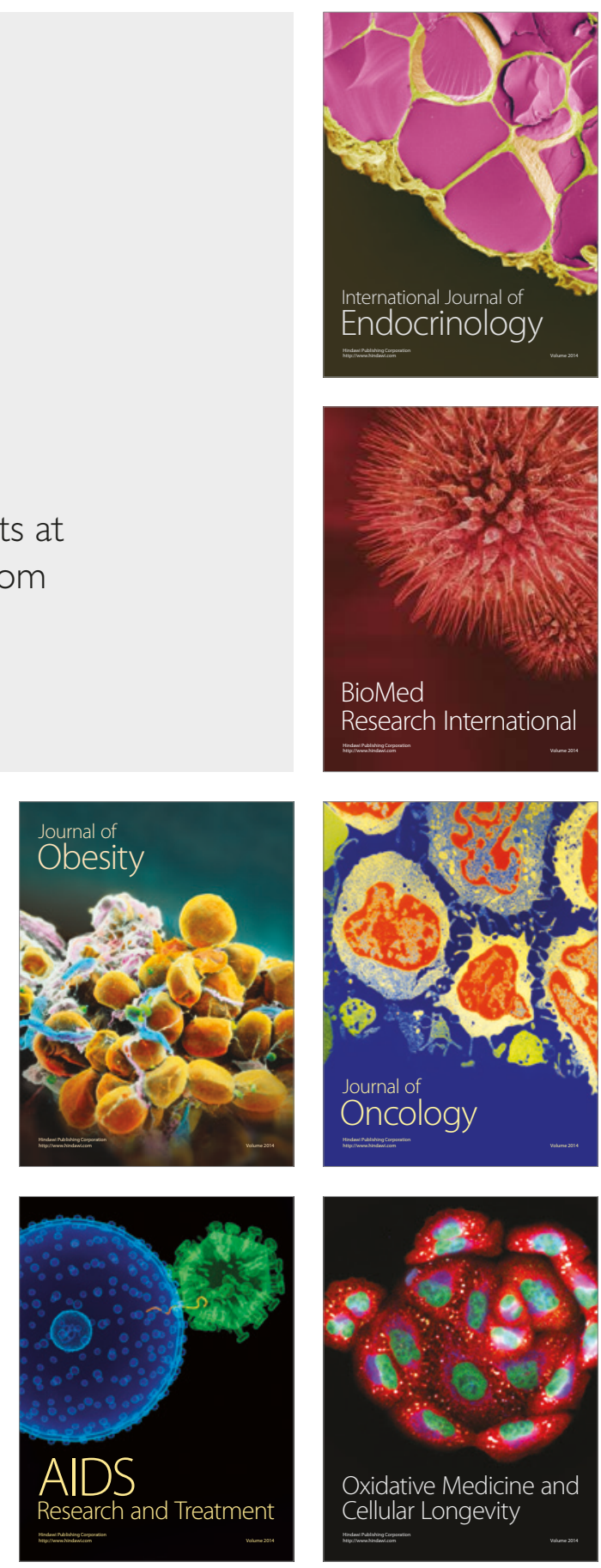